\title{
CÁCH TIẾP CẬN MỚI XÂY DỰNG ĐƯờNG ĐẶC TÍNH HỒ CHỨA BẰNG VIẸC SỬ DỤNG ẢNH VIỄN THÁM RADAR SENTINEL-1
}

\author{
Nguyễn Quốc Hiệp ${ }^{1}$, Nguyễn Anh Hùng ${ }^{1}$
}

Tóm tắt: Đường đặc tính lòng hồ chưa (quan hệ Z-F-W) được sủ dụng trong quá trình điều tiết nước trong mùa lũ và phân phối nước trong mùa kiệt. Theo thống kê gần nhất của Tổng cục Thủy lợi thi Việt Nam có khoảng 6636 hồ chứa trong đó có khoảng 474 hồ chưa đã được xác định đường đặc tính và 6162 hồ chứa có đường đặc tính chura được xác định. Để điều tiết hoặc phân phối nước cho các hồ chứa chura được xác định đường đặc tính, hiện tại các đơn vị quản lý hồ đang coi nhu đường đặc tính của nó là tuyến tính theo một đường thẳng tù mưc nước chết đến mưc nuớc dâng bình thường. Với cách làm này, kết quả xác định dung tích hồ thường có sai số tương đối lớn nhung vẫn được sủ dụng để vận hành hồ chứa. Ngay cả nhũng hồ chứa đã được xác định đường đặc tính thì bản thân đường đặc tính cũng không còn chính xác do hồ được xây dụng tù lâu, quá trình bồi lắng, xói lở làm thay đổi địa hình lòng hồ, nên chúng cũng cần phải kiểm tra để hiệu chinh lại. Bài viết này giới thiệu cách tiếp cận mới của Trung tâm Công nghệ phần mềm Thuỷ lợi trong việc sử dụng ảnh Synthetic Aperture Radar (SAR) Sentinel-1 vào việc xây dụng hoạc hiệu chỉnh lại đường đặc tính hồ chứa cho các hồ có dung tích trên một triệu m³ trên địa bàn tỉnh Hà Tĩnh, Việt Nam.

Tù̀ khóa: Viễn thám, Sentinel-1, Đương đặc tính hồ chía.

Ban Biên tập nhận bài: 12/08/2019 Ngày phản biện xong: 05/10/2019 Ngày đăng bài:25/10/2019

\section{1. Đặt vấn đề}

Việt Nam có 108 lưu vực sông với khoảng 3450 sông, suối tương đối lớn trong đó có 9 hệ thống sông lớn có diện tích lưu vực lớn hơn $10.000 \mathrm{~km}^{2}$, gồm các lưu vực sông Hồng, Thái Bình, Bằng Giang - Kỳ Cùng, Mã, Cả, Vu Gia Thu Bồn, Ba, Đồng Nai và sông Cửu Long [1]. Tổng lượng nước mặt trung bình hằng năm khoảng 830-840 tỷ $\mathrm{m}^{3}$, trong đó hơn 60\% lượng nước được sản sinh từ nước ngoài, chỉ có khoảng 310-320 tỷ $\mathrm{m}^{3}$ được sản sinh trên lãnh thổ Việt Nam [2]. Lượng nước bình quân đầu người trên $9.000 \mathrm{~m}^{3} /$ năm. Nước dưới đất cũng có tổng trữ lượng tiềm năng khoảng 63 tỷ $\mathrm{m}^{3} /$ năm, phân bố ở 26 đơn vị chứa nước lớn, nhưng tập trung chủ yếu ở Đồng bằng Bắc Bộ, Nam Bộ và khu vực Tây Nguyên.

Về hồ chứa, các lưu vực sông có dung tích hồ chứa lớn gồm: sông Hồng (khoảng 30 tỷ $\mathrm{m}^{3}$ ); sông Đồng Nai (trên 10 tỷ $\mathrm{m}^{3}$ ); sông Sê San (gần 3,5 tỷ $\mathrm{m}^{3}$ ); sông Mã, sông Cả, sông Hương, sông Vu Gia - Thu Bồn và sông Srêpok (có tổng dung tích hồ chứa từ gần 2 tỷ $\mathrm{m}^{3}$ đến 3 tỷ $\mathrm{m}^{3}$ ). Vai trò của các công trình hồ chứa để phân phối lại dòng chảy của sông theo thời gian và không gian cho thích ứng với nhu cầu dùng nước của các ngành kinh tế, làm cơ sở cho việc quy hoạch, sử dụng tài nguyên nước hợp lý, đảm bảo cân đối giữa cung và cầu và giảm nhẹ lũ cho hạ lưu là một việc làm cần thiết. Với tổng lượng tài nguyên nước phong phú như vậy nhưng hàng năm vẫn xảy ra tình trạng úng lụt và hạn hán, thiếu nước sinh hoạt, v.v... Một số nguyên nhân chủ yếu dẫn đến tình trạng nêu trên gồm: (i) hơn một nửa nguồn tài nguyên nước của Việt Nam bắt nguồn từ ngoài biên giới, nguồn tài nguyên nước phân

${ }^{1}$ Trung tâm Công nghệ phần mềm Thủy lợi

Email:nguyenquochiep@cwrs-au.vn,anhhungbk81@gmail.com 
bố không đều theo không gian và thời gian; (ii) Nhu cầu nước ngày càng gia tăng phục vụ phát triển kinh tế-xã hội; (iii) Ô nhiễm nguồn nước ngày càng tăng cả về mức độ, quy mô, nhiều nơi có nước nhưng không thể sử dụng do nguồn nước bị ô nhiễm; (iv) Biến đổi khí hậu và nước biển dâng, xâm nhập mặn, rừng đầu nguồn bị suy giảm đã và đang tác động tiêu cực đến nguồn tài nguyên nước.

Để vận hành hồ chứa hiệu quả, đường cong đặc tính hồ chứa (Z-F-W) đóng một vai trò quan trọng [3]. Đường đặc tính lòng hồ chứa (quan hệ $\mathrm{Z}-\mathrm{F}-\mathrm{W}$ ) được sử dụng trong quá trình điều tiết nước trong mùa lũ và phân phối nước trong mùa kiệt. Theo thống kê gần nhất của Tổng cục Thủy lợi thì Việt Nam có khoảng 6636 hồ chứa trong đó có khoảng 474 hồ chứa đã được xác định đường đặc tính và 6162 hồ chứa có đường đặc tính chưa được xác định.

Đường cong Z-F-W của các hồ chứa còn lại được thiết lập bằng cách sử dụng mối quan hệ tuyến tính giữa các đặc điểm đáy của hồ chứa. Tuy nhiên, mối quan hệ tuyến tính có thể gây ra một lỗi rất lớn do điều kiện hình dạng phi tuyến tính của lớp địa hình hồ chứa [4]. Đường cong ZF-W có thể được xây dựng với độ chính xác cao bằng các phương pháp đo trường nhưng phương pháp này rất tốn kém và mất thời gian tính toán, đặc biệt đối với các hồ chứa lớn. Các nhà nghiên cứu đã phát triển đường cong $\mathrm{Z}-\mathrm{F}-\mathrm{W}$ dựa trên đơn giản hóa tuyến tính, tương tự như mối quan hệ tuyến tính. Tuy nhiên, đơn giản hóa tuyến tính có thể tạo ra các lỗi lớn trong hoạt động tối ưu [5]. Nghiên cứu này giới thiệu một phương pháp để xác định đường cong Z-F-W phi tuyến của hồ chứa bằng cách sử dụng hình ảnh radar viễn thám miễn phí Sentinel-1. Cách tiếp cận này cho thấy sự cải thiện trong việc xác định các đường cong Z-F-W của hồ chứa.

\section{Thu thập dữ liệu và Phương pháp nghiên cứu}

\subsection{Thu thập dĩ liệu}

Để xác định đường đặc tính lòng hồ chứa cần có số liệu mực nước $(Z)$, số liệu diện tích mặt hồ
(F) và dung tích hồ chứa (W) ứng với mực nước đó. Số liệu quan trắc cao trình mực nước hồ chứa được thu thập từ Tổng cục Thủy lợi thuộc Bộ NN\&PTNT trên trang http://thuyloivietnam.vn. Diện tích bề mặt nước hồ chứa được tính từ kết quả phân tích ảnh vệ tinh miễn phí Sentinel-1 thu thập từ European Space Agency (ESA) trên trang https://search.asf.alaska.edu. Dựa trên đường quan hệ giữa cao trình mực nước và diện tích bề mặt hồ (Z-F) nhiều năm, mối quan hệ giữa cao trình mực nước và dung tích hồ chứa (Z-W) được tính toán theo công thức hình chóp cụt.

Diện tích mặt hồ chứa được xác định dựa vào kết quả giải đoán ảnh vệ tinh. Trước khi có ảnh vệ tinh radar miễn phí Sentinel-1 thì việc ứng dụng ảnh vệ tinh để giải đoán diện tích mặt hồ là không khả thi bởi các ảnh miễn phí có độ phân giải trung bình và thấp nên sai số sẽ cao. Thêm vào đó đa phần các ảnh miễn phí là ảnh quang học là loại ảnh bị ảnh hưởng bởi mây mù che phủ mặt hồ chứa. Nếu sử dụng ảnh viễn thám thương mại độ phân giải siêu cao thì chi phí lại quá cao so với phương pháp đo đạc truyền thống. Từ năm 2015, cơ quan ESA của Châu Âu bắt đầu chia sẻ miễn phí các loại ảnh vệ tinh Sentinel với độ phân giải cao giúp mở ra cách tiếp cận mới xác định đường đặc tính hồ chứa. Vệ tinh Sentinel-1A và Sentinel-1B cung cấp ảnh radar với độ phân giải không gian mặt đất là $10 \mathrm{~m}$, không bị ảnh hưởng bởi mây che phủ, không phụ thuộc vào thời tiết, rất nhạy cảm với bề mặt nước. Vì vậy, ảnh Sentinel-1 là nguồn tư liệu quý báu để xác định đường đặc tính hồ với chi phí thấp. Đối với khu vực Việt Nam, cứ 12 ngày sẽ có một ảnh Sentinel-1 chụp cùng một khu vực và hiện nay đã được rút ngắn lại là 6 ngày có một ảnh do 2 vệ tinh $\mathrm{S} 1 \mathrm{~A}$ và $\mathrm{S} 1 \mathrm{~B}$ bay chụp đan xen nhau 180 độ.

\subsection{Phương pháp nghiên cúu}

Có hai phương pháp để xác định diện tích bề mặt hồ chứa. Phương pháp thứ nhất là sử dụng các phần mềm chuyên dụng như ArcGIS, ENVI,... để khoanh vi diện tích bề mặt hồ chứa trên ảnh. Phương pháp này thực hiện khá đơn giản vì người số hóa có thể dễ dàng xác định đâu 


\section{BÀI BÁO KHOA HỌC}

là hồ chứa, đâu là nhiễu do bóng địa hình gây ra. Tuy nhiên phương pháp này khó khả thi vì số lượng hồ chứa trên cả nước là rất lớn, số lượng ảnh cũng nhiều, chi phí nhân công để thực hiện công việc này khá là tốn kém. Phương pháp thứ hai là sử dụng thuật toán để tự động nhận biết được điểm ảnh của từng hồ chứa. Trong nghiên cứu này phương pháp tự động giải đoán ảnh được sử dụng để xác định diện tích mặt nước hồ.
Phương pháp này khả thi cho các lĩnh vực nghiên cứu lớn với chi phí và thời gian hợp lý. Tuy nhiên, việc xác định diện tích bề mặt hồ chứa thông qua giải đoán hình ảnh đòi hỏi các thuật toán tối ưu. Để xác định thuật toán tối ưu, cần phải hiểu bản chất của hình ảnh radar cũng như các kỹ năng lập trình và xử lý dữ liệu lớn. Hình 1 và hình 2 cho thấy cách tiếp cận và quy trình xây dựng đường cong $\mathrm{Z}-\mathrm{F}-\mathrm{W}$ của hồ chứa.

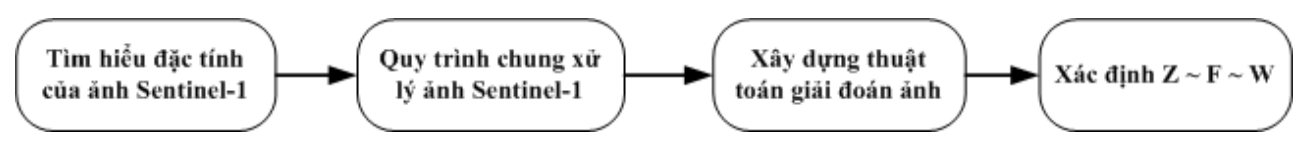

Hình 1. Các buớc nghiên cứ xác định đường đặc tính hồ chứa Z-F-W

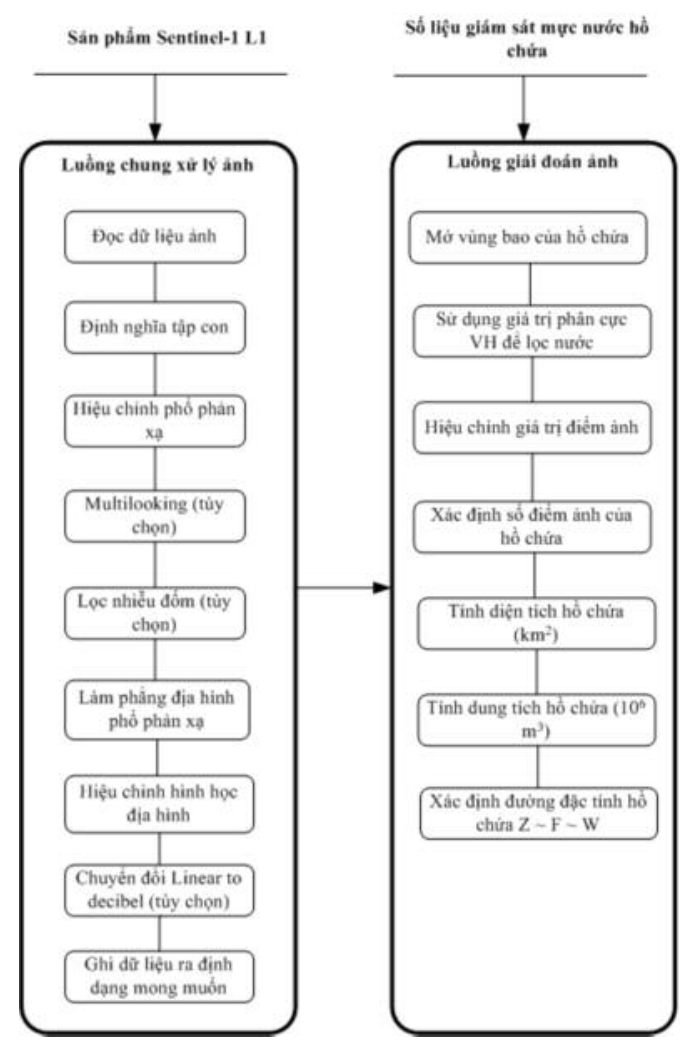

Hìn 2. Quy trình xây dưng đường đặc tính hồ chưa

\subsection{Xây dụng đường đặc tính hồ chứa Z-} $\boldsymbol{F}-\boldsymbol{W}$

\section{Xủ lý ảnh Sentinel-1}

Sử dụng phần mềm SNAP Desktop nạp danh sách dữ liệu ảnh vệ tinh vào cửa sổ quản lý tập tin, cắt vùng nghiên cứu. Nếu mặc đinh sử dụng độ phân giải ảnh là $10 \mathrm{~m}$ thì chỉ cần hiệu chỉnh phổ phản xạ (radiometric calibration) và hiệu chỉnh hình học (geometric calibration) là đủ [6]. Hiệu chỉnh phổ phản xạ là để tạo ra một hình ảnh trong đó giá trị của từng pixel liên quan trực tiếp đến tán xạ ngược của bề mặt. Phép hiệu chỉnh này rất cần thiết để phân tích hình ảnh một cách định lượng. Hiệu chỉnh hình học là để khắc phục các biến dạng nghiêng (Slant Range), layover, bóng địa hình (shadow), foreshortening. Thuật 
toán hiệu chỉnh hình học sử dụng dữ liệu DEM $30 \mathrm{~m}$ để chỉnh sửa và hình ảnh sẽ được điều chỉnh theo đúng hướng của nó.

Đối với những hồ chứa có đường mép nước trơn, không phức tạp thì chúng tôi sử dụng Multilooking chuyển độ phân giải ảnh về $20 \mathrm{~m}$ nhằm giảm dung lượng xử lý ảnh. Ngoài ra chúng tôi chuyển dữ liệu kênh ảnh Sigma0_VH từ tuyến tính về decibel và lưu dưới tên Sigma0_VH_db.

\section{Vùng làm việc}

Một vùng buffer được sử dụng để xác định vùng giải đoán hồ chứa, các điểm ảnh nằm ngoài vùng buffer sẽ được xem xét. Sử dụng vùng buffer giúp giảm số lượng các điểm ảnh phải xử lý, ngoài ra còn giúp khoanh vùng được khu vực là hồ chứa. Ví dụ đối với các sông lớn có đập dâng xây chắn để chắn để ngăn nước tạo thành hồ chứa thì vùng buffer sẽ lấy ranh giới của sông đến phạm vi của đập dâng (minh họa trong hình 4).

Xác định ngương phản xa ngược là nước

Dựa vào chuỗi dữ liệu ảnh Sentinel-1 từ một năm trở lên ứng với giá trị mực nước đo tự động tại thời điểm ảnh được chụp tại vùng nghiên cứu, chúng ta xác định được mực nước thấp nhất và mực nước cao nhất trong chuỗi thời gian dữ liệu. Sử dụng phần mềm SNAP Desktop để xác định ngưỡng phản xạ ngược của ảnh Sentinel-1 chụp tại thời điểm có mực nước thấp nhất và ảnh chụp tại thời điểm có mực nước cao nhất. Giá trị tán xạ ngược tại thời điểm hồ chứa có mực nước thấp nhất sẽ thấp hơn giá trị tán xạ ngược tại thời điểm hồ chứa có mực nước cao nhất. Độ cao của mực nước hồ sẽ có giá trị tỷ lệ thuận với ngưỡng giá trị tán xạ ngược để tách nước hồ chứa từ ảnh. Nghĩa là chúng ta chỉ xác định ngưỡng tại hai thời điểm mà hồ chứa có mực nước thấp nhất và cao nhất. Ngưỡng giá trị tán xạ ngược ứng với mực nước tại các thời điểm khác sẽ được nội suy dựa trên hai giá trị trên.

\section{Loại địa hình và bóng địa hình}

Để loại bỏ khu dân cư, núi rừng, đường xá thì chúng tôi sử dụng kênh Sigma0_VH_db có giá trị nhỏ hơn hoặc bằng ngưỡng lọc nước. Riêng bóng địa hình do bị mất giá trị nên có giá trị gần giống với bề mặt nước thì chúng tôi sử dụng giá trị của kênh projectedLocalIncidenceAngle là kết quả đầu ra trong bước hiệu chỉnh hình học và địa hình để loại bỏ bóng địa hình.

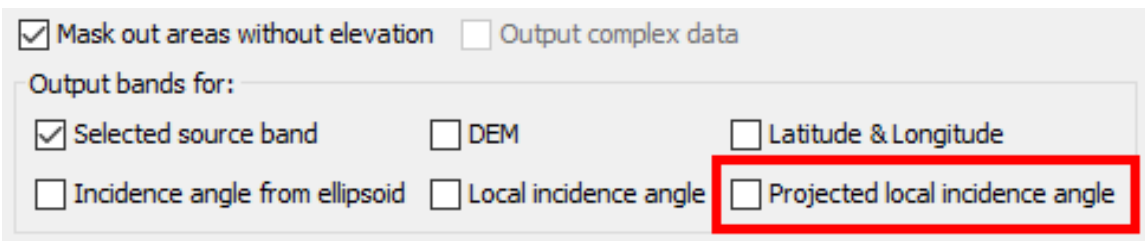

Hình 3. Sư dụng kênh "projected local incidence angle” để loại bỏ bóng địa hình

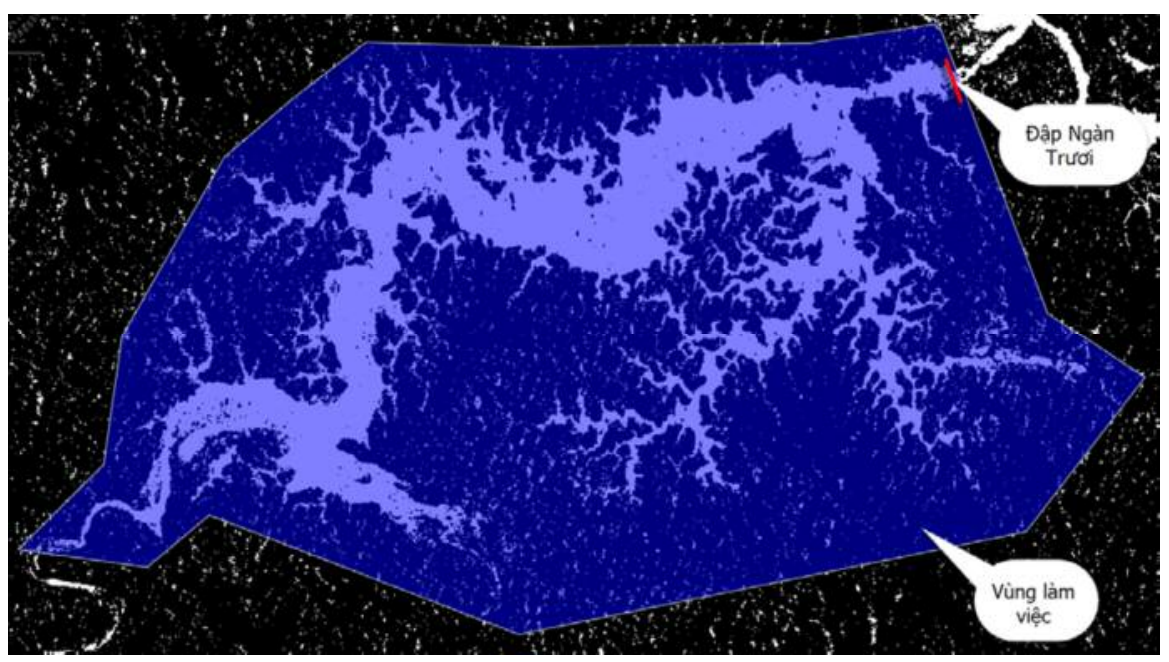

Hình 4. Minh họa các điểm ảnh được lọc theo ngững tán $x a$ ngươc 


\section{Chũa các điểm ảnh là nước và ngược lại}

Thường thì giá trị ngưỡng tán xạ ngược để tách nước có giá trị nhỏ hơn vào thời điểm khô hạn khi mà mực nước hồ chứa thấp trong năm so với các thời điểm mà mực nước hồ chứa ở mức cao hơn. Khi sử dụng chức năng tạo Band Maths của phần mềm SNAP Desktop để tách nước dựa vào giá trị ngưỡng tán xạ ngược của kênh ảnh VH, ví dụ Sigma0_VH_db $<=-24$, sẽ khiến cho một số điểm ảnh là nước nhưng lại bị loại vì giá trị $\mathrm{VH}$ db lớn hơn -24 như trong ví dụ. Hình 3 bên dưới minh họa các điểm ảnh là nước nhưng bị loại do lấy ngưỡng nhỏ.

Trong trường hợp này chúng tôi phát triển một thuật toán lan truyền để xác định chuỗi các điểm không phải là nước. Từ danh sách chuỗi các điểm ảnh không phải là nước này thì chúng tôi chỉ xét các chuỗi có số lượng điểm ảnh nhỏ hơn hoặc bằng 20 nếu độ phân giải của ảnh là $10 \mathrm{~m}$ hoặc nhỏ hơn hoặc bằng 5 nếu độ phân giải của ảnh là $20 \mathrm{~m}$, đổi giá trị của các điểm ảnh này từ giá trị 0 (không phải là nước) về giá trị 1 (là nước).

Trên hình 4 có thể thấy tuy đã loại bỏ bóng địa hình nhưng vẫn có các điểm ảnh là bóng địa hình nhưng lại được giải đoán là nước cần phải loại bỏ. Chúng tôi sử dụng thuật toán lan truyền như trên để xác định chuỗi các điểm ảnh là nước. Từ danh sách chuỗi các điểm ảnh là nước này thì chúng tôi chỉ xét các chuỗi có số lượng điểm ảnh nhỏ hơn hoặc bằng 20 nếu độ phân giải của ảnh là $10 \mathrm{~m}$ hoặc nhỏ hơn hoặc bằng 5 nếu độ phân giải của ảnh là $20 \mathrm{~m}$, đổi giá trị của các điểm ảnh này từ giá trị 1 (là nước) về giá trị 0 (không phải là nước).

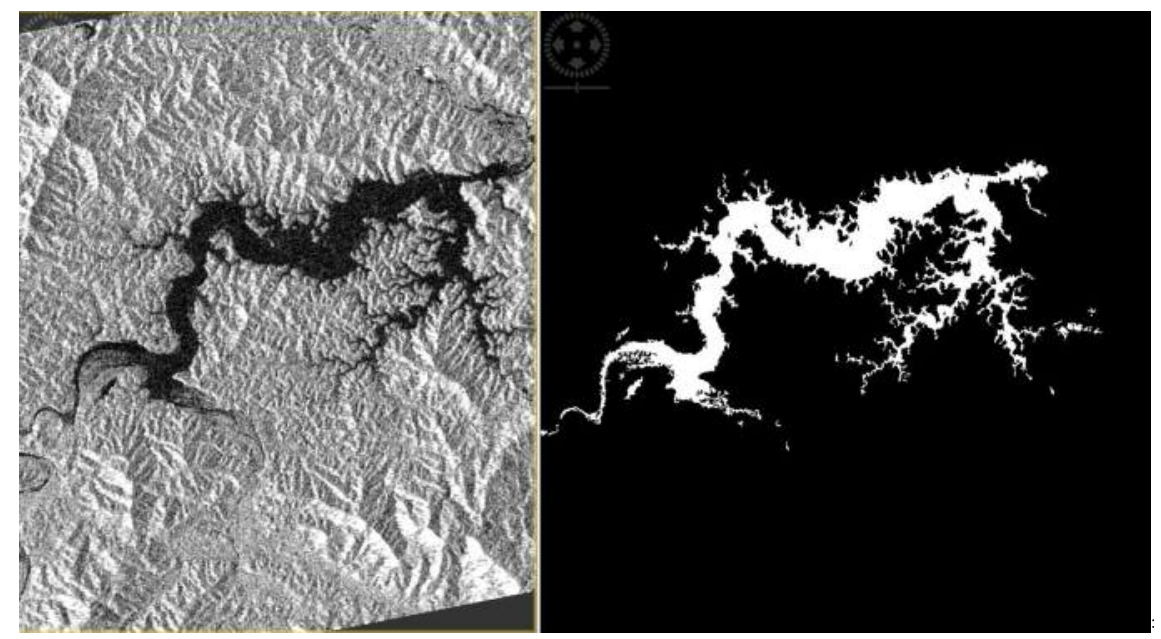

Hình 5. Kết quả giải đoán ảnh xác định diện tích hồ chứa nước Ngàn Truơi, Hà Tĩnh, Việt Nam

\section{Xác định đường đặc tính diện tích mặt nước hồ $(Z-F)$}

Dựa vào số liệu mực nước hồ được đo thủ công hoặc đo tự động từ trạm quan trắc ứng với ngày giải đoán ảnh được thu thập, tiến hành xác định quan hệ Z-F dựa vào tập hợp các cặp giá trị mực nước hồ và diện tích mặt hồ được giải đoán từ ảnh. Diện tích mặt nước hồ tại thời điểm giải đoán ảnh được tính bằng số điểm ảnh là nước nhân với diện tích của một điểm ảnh. Tùy theo độ phân giải của ảnh thì diện tích của một điểm ảnh cũng khác nhau, đối với độ phân giải là $10 \mathrm{~m}$ thì diện tích của một điểm ảnh là $100 \mathrm{~m}^{2}$, ứng với độ phân giải $20 \mathrm{~m}$ thì diện tích của một điểm ảnh là $400 \mathrm{~m}^{2}$.

\section{Xác định đường đặc tính dung tích hồ}

Trong nghiên cứu này, mực nước thấp nhất được gọi là mực nước chết (Z0) trong khi mực nước cao hơn mực nước chết $(\mathrm{Zi})$ được gọi là mực nước hữu ích. Thể tích hồ chứa bị giới hạn giữa mực nước chết và mực nước hữu ích được gọi là dung tích hữu ích. Dung tích hữu ích được 
xác định dựa trên chuỗi dữ liệu quan hệ giữa cao trình mực nước và diện tích bề mặt hồ chứa. Nó được tính bằng công thức hình chóp cụt (Công thức 1).

$$
\mathrm{W}_{\mathrm{i}}=\sum_{\mathrm{i}=0}^{\mathrm{n}} \frac{\left(\mathrm{Z}_{\mathrm{i}+1}-\mathrm{Z}_{\mathrm{i}}\right)}{3}\left(\mathrm{~F}_{\mathrm{i}}+\mathrm{F}_{\mathrm{i}+1}+\sqrt{\mathrm{F}_{\mathrm{i}} \mathrm{F}_{\mathrm{i}+1}}\right)
$$

Trong đó i là vị trí thứ i trong chuỗi giá trị cao trình mực nước được sắp xếp tăng dần từ bản ghi thứ 0 đến bản ghi thứ $\mathrm{n} ; \mathrm{W}_{\mathrm{i}}$ là dung tích hữu ích của hồ chứa tại cao trình mực nước tại vị trí thứ $\mathrm{i}$ trong chuỗi dữ liệu; $\mathrm{Z}_{\mathrm{i}}$ là cao trình mực nước tại vị trí thứ i trong chuỗi dữ liệu; $F_{i}$ là diện tích bề mặt hồ chứa ứng với cao trình mực nước tại vị trí thứ i trong chuỗi dữ liệu.

\section{Kết quả và Thảo luận}

Nghiên cứu này thử nghiệm phương pháp đề xuất xây dựng đường cong Z-F-W cho ba hồ chứa của tỉnh Hà Tĩnh là Rác, Kẻ Gỗ và Ngàn Trươi (Hình 6). Các hồ chứa này có các trạm quan trắc tự động đo mực nước của hồ chứa. Dữ liệu tham khảo quan hệ Z-F-W cho các hồ chứa Rác, Kẻ Gỗ và Ngàn Trươi được lấy từ các quy trình vận hành hồ chứa hiện tại đã được UBND tỉnh Hà Tĩnh phê duyệt.
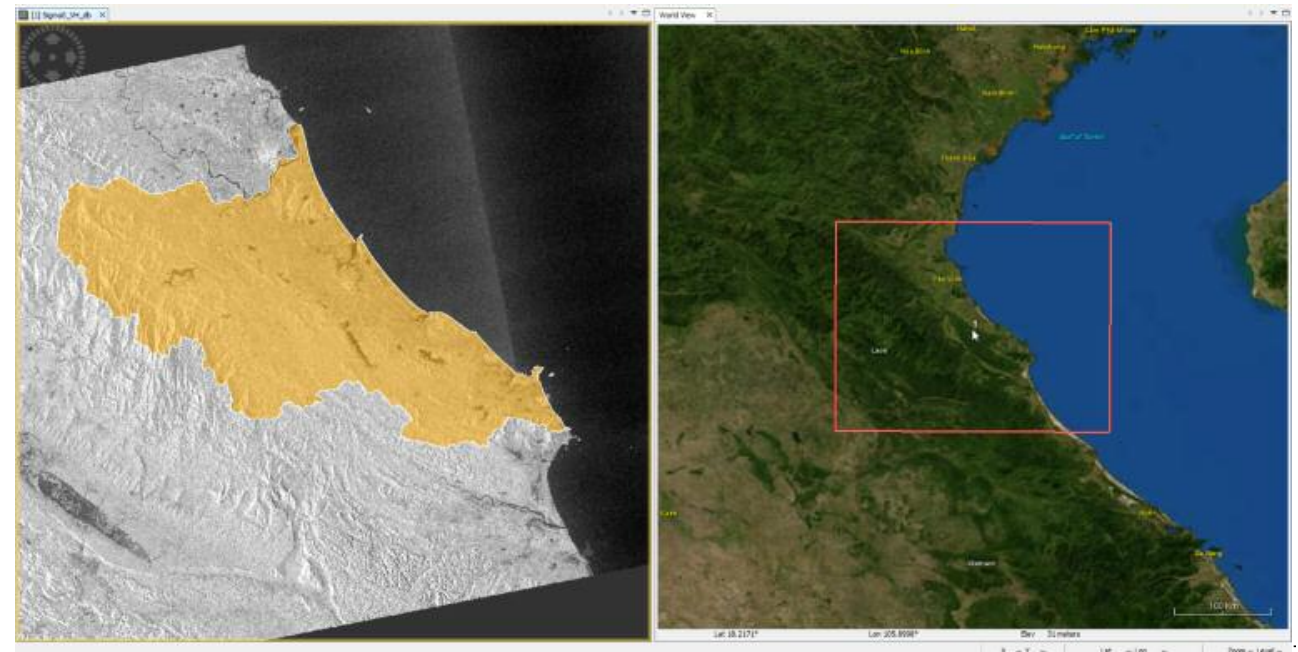

Hình 6. Khu vục nghiên cúu, tỉnh Hà Tĩnh, Việt Nam

\subsection{Xác định đường đặc tính hồ chứa Sông Rác}

Hồ chứa nước Sông Rác thuộc địa phận xã Cẩm Lạc, huyện Cẩm Xuyên, tỉnh Hà Tĩnh, được khởi công xây dựng năm 1986, được bàn giao cho Công ty trách nhiệm hữu hạn một thành viên Thủy lợi Nam Hà Tĩnh quản lý vận hành khai thác từ năm 1995. Trong giai đoạn 19911994, hồ chứa nước Sông Rác vừa được tiếp tục xây dựng, vừa được vận hành khai thác từng phần để phục vụ sản xuất nông nghiệp của huyện Cẩm Xuyên. Năm 2012 hồ đã nâng cấp theo chương trình an toàn hồ chứa và xây dựng tràn xả lũ, hình thức đập tràn Oxipherop tràn tự do với chiều rộng tràn $\mathrm{B}=70 \mathrm{~m}$.

3.2 Xác định đường đặc tính hồ chứa Kẻ Gỗ
Hồ chứa nước Kẻ Gỗ trên sông Rào Cái thuộc xã Cẩm Mỹ, huyện Cẩm Xuyên, tỉnh Hà Tĩnh, cách thành phố Hà Tĩnh khoảng $20 \mathrm{~km}$ về phía Tây. Công trình được khởi công xây dựng ngày 26/3/1976 đến tháng 02 năm 1978 bắt đầu tích nước để sử dụng. Năm 1983, công trình hoàn thành và chính thức đưa vào khai thác.

\subsection{Xác định đường đặc tính hồ chứa Ngàn Truoi \\ Hồ chứa nước Ngàn Trươi được Bộ Nông nghiệp và Phát triển nông thôn và UBND tỉnh Hà Tĩnh cho khởi công ngày 14/6/2009, phục vụ tưới khoảng 32.334 ha đất canh tác nông nghiệp ở các huyện Hương Sơn, Vũ Quang, Đức Thọ, Can Lộc, Nghi Xuân và một phần phía Bắc huyện Thạch Hà và thị xã Hồng Lĩnh.}




\section{BÀI BÁO KHOA HỌC}

Bảng 1. Xác định đặc tính hồ chứa nước tù̀ kết quả giải đoán ảnh và so sánh với số liệu tù bảng tra hồ Sông Rác

\begin{tabular}{|c|c|c|c|c|c|}
\hline $\begin{array}{l}\text { Mực } \\
\text { nước } \\
\text { (m) }\end{array}$ & $\begin{array}{l}\text { Dung tích đo } \\
\left(1^{6} \mathrm{~m}^{3}\right)\end{array}$ & $\begin{array}{c}\text { Số điểm } \\
\text { ảnh là nước }\end{array}$ & $\begin{array}{l}\text { Diện tích bề̀ } \\
\text { mặt giải đoán } \\
\left(\mathbf{k m}^{2}\right)\end{array}$ & $\begin{array}{c}\text { Dung tích } \\
\text { giải đoán } \\
\left(10^{6} \mathrm{~m}^{3}\right)\end{array}$ & $\begin{array}{c}\text { Sai số } \\
\text { dung } \\
\text { tích (\%) }\end{array}$ \\
\hline 18.5 & 61.71 & 26589 & 10.6356 & 61.71 & 0 \\
\hline 19 & 67.07 & 29182 & 11.6728 & 67.29 & 0.33 \\
\hline 19.5 & 70.52 & 29507 & 11.8028 & 73.16 & 3.74 \\
\hline 20.5 & 83.02 & 32670 & 13.068 & 85.59 & 3.1 \\
\hline 21 & 92.07 & 33829 & 13.5316 & 92.24 & 0.18 \\
\hline 21.5 & 99.17 & 34477 & 13.7908 & 99.07 & 0.1 \\
\hline 22 & 106.27 & 35362 & 14.1448 & 106.05 & 0.21 \\
\hline 22.5 & 113.81 & 36035 & 14.414 & 113.19 & 0.54 \\
\hline 23 & 121.34 & 36330 & 14.532 & 120.43 & 0.75 \\
\hline 23.5 & 129.25 & 37746 & 15.0984 & 127.84 & 1.09 \\
\hline
\end{tabular}

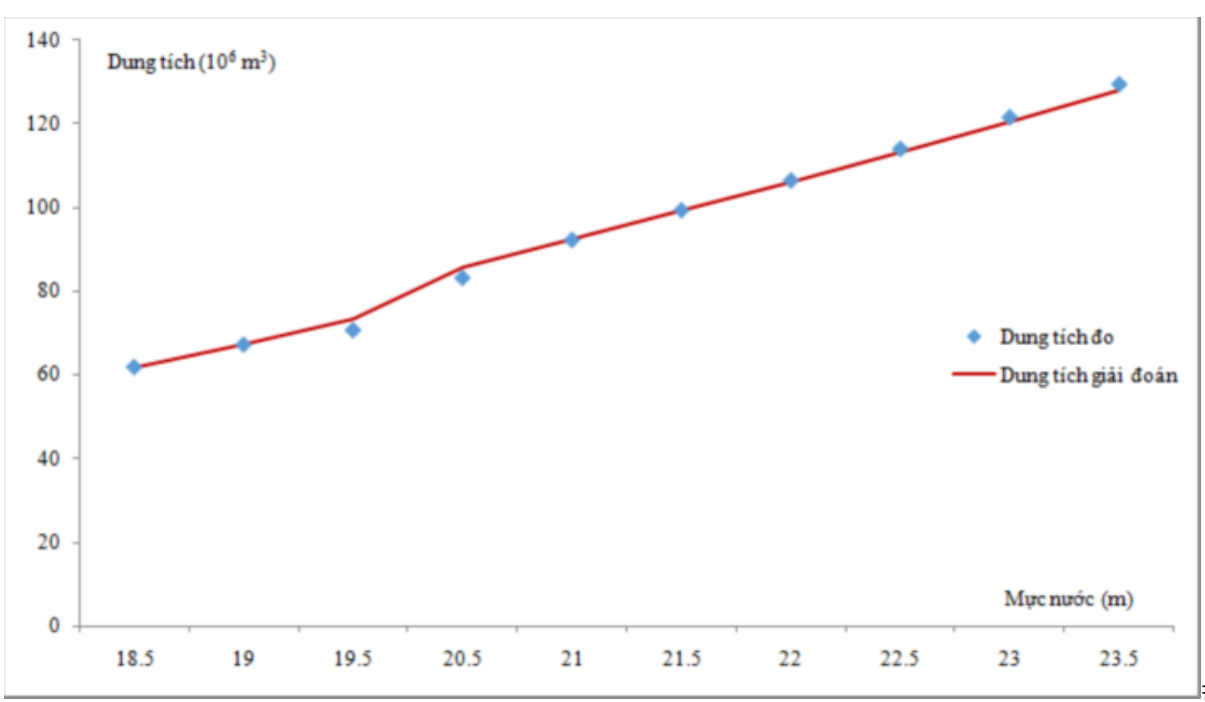

Hình 7. Đồ thị so sánh đưòng $Z \sim W$ giũa đo thực tế và giải đoán tù ảnh Sentinel-1 của hồ Sông Rác

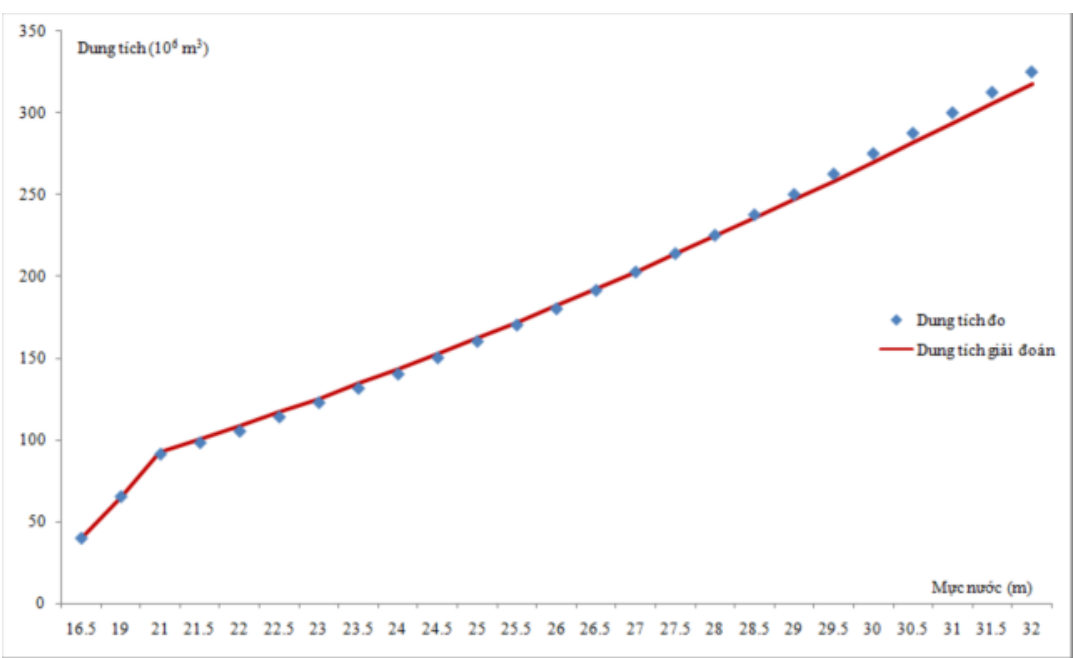

Hình 8. Đồ thị so sánh đường $Z \sim W$ giữa đo thực tế và giải đoán tù ảnh Sentinel-1 của hồ Kẻ Gỗ 
Bảng 2. Xác định đặc tính hồ chứa nuớc tù kết quả giải đoán ảnh và so sánh với số liệu tù bảng tra hồ Kẻ Gố

\begin{tabular}{|c|c|c|c|c|c|}
\hline $\begin{array}{l}\text { Mực } \\
\text { nước } \\
\text { (m) }\end{array}$ & $\begin{array}{l}\text { Dung tích đo } \\
\left(10^{6} \mathrm{~m}^{3}\right)\end{array}$ & $\begin{array}{l}\text { Số điểm } \\
\text { ảnh là nước }\end{array}$ & $\begin{array}{l}\text { Diện tích bề măt } \\
\text { giải đoán }\left(\mathbf{k m}^{2}\right)\end{array}$ & $\begin{array}{l}\text { Dung tích giải } \\
\text { đoán }\left(10^{6} \mathrm{~m}^{3}\right)\end{array}$ & $\begin{array}{c}\text { Sai số } \\
\text { dung tích } \\
(\%) \\
\end{array}$ \\
\hline 16.5 & 39.5 & 20386 & 8.1544 & 39.5 & 0 \\
\hline 19 & 65 & 30574 & 12.2296 & 64.81 & 0.29 \\
\hline 21 & 91 & 39315 & 15.726 & 92.69 & 1.86 \\
\hline 21.5 & 98 & 40738 & 16.2952 & 100.69 & 2.74 \\
\hline 22 & 105 & 40880 & 16.352 & 108.85 & 3.67 \\
\hline 22.5 & 113.75 & 41635 & 16.654 & 117.1 & 2.95 \\
\hline 23 & 122.5 & 42480 & 16.992 & 125.51 & 2.46 \\
\hline 23.5 & 131.25 & 46346 & 18.5384 & 134.39 & 2.39 \\
\hline 24 & 140 & 45259 & 18.1036 & 143.55 & 2.54 \\
\hline 24.5 & 150 & 47049 & 18.8196 & 152.78 & 1.85 \\
\hline 25 & 160 & 48574 & 19.4296 & 162.34 & 1.46 \\
\hline 25.5 & 170 & 50050 & 20.02 & 172.2 & 1.29 \\
\hline 26 & 180 & 50879 & 20.3516 & 182.29 & 1.27 \\
\hline 26.5 & 191.25 & 51760 & 20.704 & 192.55 & 0.68 \\
\hline 27 & 202.5 & 52954 & 21.1816 & 203.02 & 0.26 \\
\hline 27.5 & 213.75 & 54730 & 21.892 & 213.79 & 0.02 \\
\hline 28 & 225 & 54833 & 21.9332 & 224.75 & 0.11 \\
\hline 28.5 & 237.5 & 55877 & 22.3508 & 235.82 & 0.71 \\
\hline 29 & 250 & 57523 & 23.0092 & 247.16 & 1.14 \\
\hline 29.5 & 262.5 & 57751 & 23.1004 & 258.69 & 1.45 \\
\hline 30 & 275 & 58628 & 23.4512 & 270.33 & 1.7 \\
\hline 30.5 & 287.5 & 58616 & 23.4464 & 282.05 & 1.9 \\
\hline 31 & 300 & 59507 & 23.8028 & 293.86 & 2.05 \\
\hline 31.5 & 312.5 & 59787 & 23.9148 & 305.79 & 2.15 \\
\hline 32 & 325 & 59887 & 23.9548 & 317.76 & 2.23 \\
\hline
\end{tabular}

Bảng 3. Xác định đặc tính hồ chứa nước tù kết quả giải đoán ảnh và so sánh với số liệu tù bảng tra hồ Ngàn Truơi

\begin{tabular}{|c|c|c|c|c|c|c|c|}
\hline $\begin{array}{l}\text { Mực } \\
\text { nước } \\
\text { (m) }\end{array}$ & $\begin{array}{l}\text { Dung tích } \\
\text { do }\left(10^{6} \mathrm{~m}^{3}\right)\end{array}$ & $\begin{array}{l}\text { Diện tích } \\
\text { đo }\left(\mathbf{k m}^{2}\right)\end{array}$ & $\begin{array}{c}\text { Số } \\
\text { điểm } \\
\text { ảnh là } \\
\text { nước }\end{array}$ & $\begin{array}{c}\text { Diện tích } \\
\text { giăi đoán } \\
\left(\mathbf{k m}^{2}\right)\end{array}$ & $\begin{array}{c}\text { Sai số giải } \\
\text { đoán diện } \\
\text { tích (\%) }\end{array}$ & $\begin{array}{c}\text { Dung } \\
\text { tích giải } \\
\text { đoán } \\
\left(10^{6} \mathbf{m}^{3}\right)\end{array}$ & $\begin{array}{c}\text { Sai số } \\
\text { giải đoán } \\
\text { dung } \\
\text { tích }(\%)\end{array}$ \\
\hline 27.5 & 103.01 & 13.4201 & 127286 & 12.7286 & 5.15 & 103.01 & 0 \\
\hline 28 & 110.28 & 14.0318 & 111067 & 11.1067 & 20.85 & 108.96 & 1.2 \\
\hline 29 & 124.82 & 15.2552 & 121166 & 12.1166 & 20.57 & 120.57 & 3.4 \\
\hline 30 & 139.36 & 16.4786 & 127294 & 12.7294 & 22.75 & 132.99 & 4.57 \\
\hline 30.5 & 146.63 & 17.0903 & 151344 & 15.1344 & 11.44 & 139.95 & 4.56 \\
\hline 31 & 153.9 & 17.702 & 170663 & 17.0663 & 3.59 & 148 & 3.83 \\
\hline 31.5 & 163.92 & 18.1773 & 151273 & 15.1273 & 16.78 & 156.04 & 4.81 \\
\hline 32 & 173.94 & 18.6526 & 176464 & 17.6464 & 5.39 & 164.23 & 5.58 \\
\hline 32.5 & 183.96 & 19.1279 & 185212 & 18.5212 & 3.17 & 173.27 & 5.81 \\
\hline 33 & 193.98 & 19.6032 & 192275 & 19.2275 & 1.92 & 182.71 & 5.81 \\
\hline 33.5 & 204 & 20.0785 & 190586 & 19.0586 & 5.08 & 192.28 & 5.75 \\
\hline
\end{tabular}




\section{BÀI BÁO KHOA HỌC}

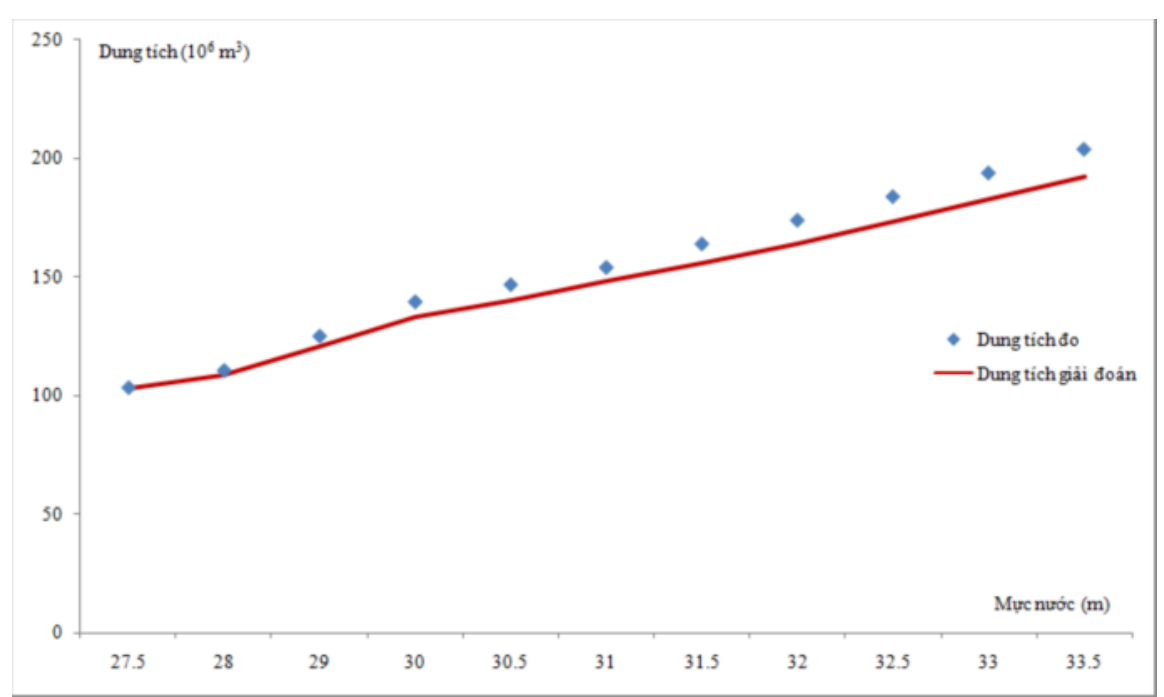

Hình 9. Đồ thị so sánh đưòng $Z \sim W$ giũa đo thục tế và giải đoán tù ảnh Sentinel-1 của hồ Ngàn Trưoi

\subsection{Thảo luận}

Trong nghiên cứu này, các mối quan hệ $\mathrm{Z}$ $\mathrm{W}$ được xác định cho ba hồ chứa và mối quan hệ $\mathrm{Z} \sim \mathrm{F}$ được xác định cho hồ chứa Ngàn Trươi có diện tích bề mặt tham chiếu. Người ta thấy rằng hầu hết các thể tích hồ chứa được tính toán hợp lý với khối lượng thực tế. Các hệ số tương quan giữa dung tích tính toán và dung tích thực tế gần bằng nhau, như được thấy trong hình $7,8 \& 9$. Về sai số tương quan của dung tích tính toán, sai số trung bình đạt được $1 \%, 1,5 \%$ và $4,1 \%$ đối với hồ chứa sông Rác, Kẻ Gô̂, và hồ chứa Ngàn Trươi tương ứng. Các phân tích bổ sung về diện tích bề mặt được tính toán sau đó được thực hiện cho Ngàn Trươi. Kết quả cho thấy hệ số tương quan đạt được là 0,93 và sai số tương đối trung bình là khoảng $10,6 \%$. Điều này chỉ ra rằng các sai số trong việc xác định diện tích bề mặt của hồ chứa có xu hướng lớn hơn các sai số thể tích. Tuy nhiên, thông tin về thể tích hồ chứa quan trọng hơn diện tích bề mặt để xây dựng quy trình vận hành hồ chứa.

\section{Kết luận}

Nghiên cứu này trình bày phương pháp và các kết quả xác định đường đặc tính hồ chứa dựa vào kết quả giải đoán ảnh vệ tinh Sentinel-1 và dữ liệu quan trắc. Kết quả giải đoán xác định quan hệ $\mathrm{Z} \sim \mathrm{W}$ cho các hồ chứa có độ chính xác trên $95 \%$. Trên cơ sở này có thể xác định nhanh chóng đường đặc tính cho các hồ chứa chưa xác định đường đặc tính lòng hồ chứa. Đường cong quan hệ Z-F-W được xác định có thể nâng cao hiệu quả quản lý và vận hành các hồ chứa.

Lời cảm ơn: Bài báo này là sản phẩm của đề tài "Nghiên cứu ứng dụng các công nghệ mới (viến thám, WEBGIS và Tự động hóa) xây dưng hệ thống thông tin quản lý, sủ dụng hiệu quả tài nguyên nước (mùa khô) theo thời gian thực nhằm ứng phó với biến đổi khi hậu, áp dụng cho tỉnh Hà Tĩnh”, mã số BĐKH.17/16-20 thuộc Chuong trình Khoa học và công nghệ ưng phó vói biến đổi khí hậu, quản lý tài nguyên và môi truờng giai đoạn 2016 - 2020. Tập thể tác giả chân thành cảm ơn Chuơng trình đã tạo điều kiện để nhóm tác giả hoàn thành bài báo này.

\section{Tài liệu tham khảo}

1. Nguyen, T.V., Elliott, R.J.R., Strobl, E.A., (2018), Hydropower generation, flood control and dam cascades: A national assessment for Vietnam. Journal of Hydrology, 560, 109-126.

2. Jolk, C., Greassidis, S., Jaschinski, S., Stolpe, H., Zindler, B., (2010), Planning and Decision Support Tools for the Integrated Water Resources Management in Vietnam. Water, 2, 711-725. 
3. Jahanshir, M.H., Heidarpour, M., Mousavi, S.F., Haghiabi, A.H., (2009), Derivation of Reservoir's Area-Capacity Equations. Journal of Hydrologic Engineering, 14, 9.

4. Gao, H., Birkett, C., Lettenmaier, D.P., (2012), Global monitoring of large reservoir storage from satellite remote sensing. Water Resour. Res., 48 (9), W09504.

5. Meyer, F., (2019), The SAR Handbook. UAF \& Chief Scientist of Alaska Satellite Facility, 2162.

\title{
A METHOD FOR CONSTRUCTING RESERVOIR AREA-STORAGE-ELEVATION CURVE USING SENTINEL-1 RADAR REMOTE SENSING IMAGE \\ Nguyen Quoc Hiep ${ }^{1}$, Nguyen Anh Hung ${ }^{1}$ \\ ${ }^{1}$ Center for Water Resources Software
}

\begin{abstract}
Reservoir elevation-area-storage $(Z-F-W)$ curves are used for regulating discharge during the flood season and allocating water supply in the dry season. According to the latest statistics of the Directorate of Water Resources, Vietnam has about 6636 reservoirs, of which the Z-F$W$ curves of 474 reservoirs have been already identified and the remaining 6162 reservoirs have no information on the Z-F-W relationship. In order to regulate or allocate water in these reservoirs, operators assume a linear relationship between the area or storage and elevation, varying from the dead to normal water level. By mean of this method, calculated area and storage are subject to large errors but they are still used to operate the reservoirs. In fact, even the reservoirs attributed with the $Z-F-W$ relationships, but the relationships may not be stationary as the reservoirs were built a long time ago with continuous sediment deposition and erosion processes that altered the reservoir bathymetry; as a result, these relationships also require corrections. This paper introduces a method for constructing the Z-F-W curves of the reservoir with the capacity larger than one million cubic meters in Ha Tinh province of Vietnam using Synthetic Aperture Radar (SAR) Sentinel-1 remote sensing image.
\end{abstract}

Keywords: Remote Sensing, Sentinel-1, Reservoir elevation-area-storage curve. 